\title{
Proposta de uma configuração para o ensino de Ciências comprometido com a ação política democrática
}

Francisco Ângelo Coutinho coutinhogambiarra@gmail.com $0000-0003-4519-2870$ Minas Gerais, Hinas Gerais, Brasil.

Kristianne Lina Figueirêdo kristiannelina@yahoo.com.br $0000-0002-0636-6455$ Universidade Federal de Viçosa, Instituto de Ciências Exatas e Tecnológicas, Florestal, Minas Gerais, Brasil.

Fábio Augusto Rodrigues e Silva fabogusto@gmail.com

Do0-0003-1245-2648

al de Ouro Preto,

Outro Preto, Minas Gerais, Brasil

\section{RESUMO}

Este é um artigo teórico e programático que fixa relações entre a aprendizagem do conhecimento científico e a ação política democrática. Inicialmente, apresenta uma tendência na filosofia da educação que se preocupa com a aprendizagem de conteúdos e a vida social e política do estudante. Ao mesmo tempo, procura-se mostrar que, no caso do gerenciamento do conhecimento científico, a efetivação desta proposta é uma necessidade urgente, uma vez que a ciência produz e faz circular conhecimentos que têm profundos impactos na sociedade. Em seguida, uma proposta metodológica para o tratamento do conhecimento científico e a ação política democrática é delineada. Questões sobre o aperfeiçoamento da proposta, sobre formação de professores e sobre os tempos e espaços para o exercício da democracia na escola são colocadas nas considerações finais.

PALAVRAS-CHAVE: Ação política. Ensino de ciências. Realidades colaterais. Transdisciplinaridade. Espaços de consulta. 


\section{INTRODUÇÃO}

Os contextos que vêm à mente quando se fala em ação política democrática normalmente são lugares como o Senado, o Congresso, a Assembleia Legislativa e outros espaços ocupados por políticos profissionais. Atualmente, porém, vários teóricos exploram o potencial da sociedade civil para a ação democrática (ROBERTSON, 2008, p. 30). Neste contexto de reflexão, entende-se sociedade civil como incluindo igrejas, associações de bairro, sindicatos, clubes, organizações culturais, entre muitos outros. A ideia é que estes grupos podem fornecer serviços aos seus membros e, ainda, expor injustiças nas esferas políticas e econômicas, coibir os poderes do Estado e da economia e funcionar como fóruns deliberativos sobre o destino da sociedade (ROBERTSON, 2008, p. 30).

Seguindo essa linha de raciocínio, alguns autores (por exemplo, ROBERTSON, 2008, p. 30; ROTH e DÉSAUTELS, 2002, p. 2) propõem então que a escola contribua de modo significativo com a formação de cidadãos capazes de identificar problemas, perceberem-se e atuarem como gestores da sociedade e se guiarem por valores democráticos. Para cumprir este papel, a escola deveria reconfigurarse de tal modo que haja reserva de tempo e mobilização de esforços para a construção de conhecimentos, habilidades e compromissos requeridos para a vida democrática (ROBERTSON, 2008, p. 38). Assim, ao falar-se em ação política democrática a escola seria lembrada como um espaço privilegiado.

Tais proposições fazem parte de uma tendência contemporânea nos estudos sobre filosofia da educação que, em anos recentes, mostra uma guinada em relação ao significado da educação democrática. Da questão da promoção de valores e atitudes, o foco passa a ser a motivação e o ensino sobre a participação ativa dos alunos, de forma construtiva e competente, no processo democrático. Isto, por sua vez, vem sendo impulsionado pelo conceito de democracia deliberativai (REICH, 2007). Embora existam diferentes definições e justificativas filosóficas deste conceito, todas enfatizam a ideia de que as democracias estáveis exigem que seus membros façam mais do que apenas participar do processo formal de sufrágio. Os cidadãos também devem participar ativamente nos discursos públicos por meio dos quais argumentos e opiniões sobre temas da atualidade política são debatidos, consequências de decisões anteriores são avaliadas e novos tópicos são introduzidos (REICH, 2007). Enquanto filósofos e cientistas políticos trabalham em problemas como a adequação normativa ou a articulação real da deliberação democrática, pesquisadores educacionais são confrontados com o problema de promover nos alunos a competência e a vontade de participar (REICH, 2007).

Orientado por essa necessidade, o presente artigo levanta a seguinte questão: como configurar o ensino de ciências tal que estimule o envolvimento político dos alunos em questões controversas produzidas pelo conhecimento científico? Como resposta propõe-se uma configuração metodológica para o ensino de ciências que visa favorecer e estimular a elaboração/criação de estratégias de ensino por meio de "espaços de consulta", referenciada pelas incertezas e riscos gerados pelo conhecimento científico e pelas tecnologias. Estes "espaços de consulta" são entendidos como atividades acomodadas nas escolas que possibilitam aos alunos uma compreensão da natureza de riscos e incertezas gerados pela produção e 
cidadãos na deliberação sobre os problemas da sociedade e uma orientação por valores democráticos na resolução de problemas tecnocientíficos.

Antes de dar prosseguimento a esta proposta, duas considerações precisam ser feitas. A primeira é de ordem terminológica. Normalmente utiliza-se a expressão "modelo de ensino" para exprimir ideia semelhante à que é apresentada neste artigo. No entanto, a palavra modelo carrega, entre outros, o significado de imitação ou reprodução de algo em escala diferente. Já a palavra configuração tem um significado mais próximo de "aspecto" ou "feitio", não tendo, portanto uma conotação de estrutura rígida. Estes últimos significados são os mais próximos da ideia que aqui se apresenta, pois não se trata de construir uma receita ou fórmula a ser seguida, mas ideias gerais a serem avaliadas, adaptadas, reelaboradas e confrontadas com a prática. Portanto, o que se segue não pretende ser uma solução, mas a proposta de um diálogo.

A segunda observação é sobre o nível de aplicação da proposta. O uso da expressão "ensino de ciências" sem fazer distinção entre as divisões disciplinares das ciências naturais pode dar a falsa impressão de que a proposta aplica-se exclusivamente ao ensino fundamental. Porém, a proposta foi pensada para o ensino médio, onde as disciplinas Biologia, Física e Química encontram-se separadas no currículo. O fato de não ser feita uma distinção assenta-se justamente na busca de uma maior colaboração entre as disciplinas. Esta observação não impossibilita que a proposta seja aplicada ou adaptada para o ensino fundamental ou ainda para outras modalidades, como Educação de Jovens e Adultos (EJA). Significa apenas que os autores estão limitando sua proposta ao contexto em que possuem uma formação mais ampla e experiências profissionais mais significativas.

Esclarecidos estes pontos, apresentam-se a seguir o referencial que sustenta a perspectiva do trabalho e, posteriormente, a proposta de uma configuração metodológica para o ensino de ciências e a ação política. Finalmente, nas considerações finais, são levantadas questões de pesquisa para a área de educação e formação de professores.

\section{EDUCAÇÃO EM CIÊNCIAS E AÇÃO POLÍTICA}

No que diz respeito ao ensino de ciências naturais, um abismo se formou entre os conteúdos escolares e a vida cidadã. Nestas disciplinas, a ênfase tem reincidido, principalmente, sobre a aquisição de conhecimento factual ou sobre a memorização de conceitos. Trata-se de um ensino que tem sido extremamente voltado para si mesmo, centrando-se em cobrir um excesso de fatos e conceitos (APEDOE, 2008), mas que raramente, ou nunca, envolve preparar os alunos para o exercício da cidadania e para a participação informada, crítica e responsável em situações onde os saberes da ciência estão envolvidos. É possível que isso seja consequência daquilo que Latour (1994), criticamente, chamou de "acordo moderno", um pressuposto segundo o qual a ciência será tão mais valiosa e verdadeira, tão mais 'científica', quanto mais se purificar das interferências humanas e se focar apenas na natureza.

No sentido de corrigir a situação descrita acima, vários autores (por exemplo, 
amplo: a sociedade" (FENSHAM, 2002). Isso significa ensinar a ciência enquanto processo e produção humana e não como um conjunto de verdades eternas a serem recitadas como um mantra. Quando se analisa os processos de produção e disseminação do conhecimento científico, pode-se perceber que estes não apenas estão inseridos em um contexto social, como contribuem efetivamente para a constituição deste contexto (LATOUR, 2000, pp. 11-36). Assim, tais propostas procuram romper com a ênfase em uma educação conteudista que, ao final, trata de assuntos sem o menor sentido para a vida social do aluno. Defende-se, em confronto, que o ensino de ciências esteja voltado para a participação do aluno em ações coletivas que visem entender e resolver os complexos problemas gerados pela ciência e pela tecnologia (ROTH e DÉSAUTELS, 2002, p. 13).

A proposta de um ensino de ciências voltado para as necessidades e interesses da sociedade pode ser reforçada diante do fato de que a crise das comunidades humanas, tanto local quanto globalmente, torna-se cada dia mais grave. Van Breda (2007), por exemplo, defende que o mundo está passando por uma "policrise", uma situação na qual não existe somente um único e grande problema, mas uma série de problemas sobrepostos e interconectados. Para além de uma longa lista de riscos que ameaçam as sociedades atuais, pode-se acrescentar, como se verá, as incertezas produzidas pela ciência e pela tecnologia. 


\section{EIXOS DE SUSTENTAÇÃO DA PROPOSTA}

\subsection{Sobre riscos e incertezas}

Como primeiro passo, é importante esclarecer o que significa "risco" e "incerteza". Isso se faz necessário porque estas duas palavras cobrem realidades diferentes. Segundo Callon et al. (2011, p. 19), a palavra "risco" designa um perigo bem identificado associado a um evento ou série de eventos perfeitamente descritível. Não há certeza se este evento ou série de eventos irá ocorrer de fato, apenas que é algo que pode acontecer. Já a palavra "incerteza" refere-se à uma incapacidade de antecipar as consequências das decisões que são tomadas. Nestes casos, a descrição do que pode acontecer esbarra em "núcleos de ignorância", o comportamento e as interações das entidades tornam-se enigmáticos e, em consequência, não se tem um conhecimento suficientemente preciso das opções possíveis (CALLON et al., 2011, p. 21).

Com base nisto, pode-se constatar, primeiro, que vivemos em uma "sociedade em risco", na qual já não é mais possível o distanciamento do perigo, uma vez que estes estão bem distribuídos (BECK, 1986, p. 19). Há indicações de que os sistemas naturais do planeta, dentro em pouco, não serão mais capazes de suportar as necessidades humanas básicas (COLUCCI-GRAY et al., 2012). Para se ter uma ideia, a humanidade já se apropriou de mais da metade da água doce acessível. $\mathrm{O}$ uso de $5 \%$ a $25 \%$ da água doce global excede hoje o suprimento local, o que também ocorre com $15 \%$ a $35 \%$ da água usada em irrigação. Existem indícios de que até 2030 cerca de $75 \%$ das espécies animais e vegetais estarão ameaçadas de extinção, alterando irreversivelmente a biodiversidade do planeta (MATINI e RIBEIRO, 2011).

A estes riscos, pode-se acrescentar um conjunto enorme de incertezas produzidas pela ciência e pela tecnologia. Ao contrário do que se pensa, o desenvolvimento científico e tecnológico não trouxe maior segurança (CALLON et al., 2011, p. 18) e a ciência deve ser pensada como coautora da produção de incerteza generalizada (BECK, 1986, p. 180). Por exemplo, a gestão de resíduos nucleares, as relações entre a exposição a campos eletromagnéticos e incidência de câncer, o efeito de micro-ondas sobre a saúde, as consequências da disseminação de transgênicos na natureza, a disponibilização de medicamentos no mercado de cujos efeitos colaterais são pouco conhecidos, e muitos outros que podem ser identificados como potencialmente perigosos. Nestes casos, se os efeitos nocivos se tornam aparentes, é só depois de vários anos (CALLON et al., 2011, p. 21). O estabelecimento desta distinção, ilustrada pelos exemplos, habilita a continuação da construção do referencial proposto neste trabalho.

\subsection{DELIBERANDO SOBRE RISCOS E INCERTEZAS. AS VANTAGENS DA DEMOCRACIA.}

Quando se pensa em deliberar sobre riscos e incertezas, a primeira consideração que se deve fazer é de dimensão ontológica, pois esta noção está intimamente associada com a configuração da realidade. Para explicar melhor vale a pena recorrer a uma ideia introduzida pelos teóricos da decisão e que será útil para nós: a de estados possíveis do mundo (CALLON et al., 2011, p. 20). Segundo esta noção, a situação do mundo é definida pela lista de entidades humanas e não- 
humanas que a compõe e pelas interações entre estas entidades. Na escolha de um estado possível do mundo, ou seja, no processo de tomada de decisão decidese as entidades com as quais viver e o tipo de história que se quer compartilhar com elas (CALLON et al., 2011, p. 20). Assim, tomar uma decisão é planejar um estado possível do mundo ou, segundo uma noção da futurologia, delinear um cenário.

Para detalhar isso um pouco mais, um exemplo analisado por Callon et al. (2011, p. 12-17) será apresentado e servirá como base de argumentação para a construção do que tem sido proposto aqui. Por isto, será chamado de exemplo matriz. A história diz respeito ao destino que deveria ser dado ao lixo atômico francês. Em março de 1987, o prefeito de uma cidade francesa, escolhida por suas qualidades geológicas para abrigar os resíduos atômicos, convocou uma reunião entre os vereadores e representantes da Comissão de Energia Atômica (CEA). Um dos técnicos da CEA explica na reunião que a melhor forma de eliminar estes resíduos, que serão radioativos por milhares de anos, é enterrando-os na camada geológica e que aquele local era o mais indicado. E acrescenta ele:

\footnotetext{
Na medida em que algumas dessas formações geológicas têm sido estáveis durante milhões de anos, assumimos que eles vão continuar a ser assim no período de diminuição da radioatividade dos dejetos. A estrutura geológica constituirá então uma "armadilha" de mais de 400 metros de profundidade. Esta armadilha deve permitir que o lixo seja isolado do meio ambiente até que os recipientes tenham sido destruídos por erosão e a memória do local tenha sido perdida. Este seguro geológico oferece uma imensa vantagem (apud CALLON et al., 2011, p. 13).
}

Além disso, é comunicado que o desenvolvimento do projeto trará novos empregos e consequente desenvolvimento econômico para a região.

A notícia se espalhou em poucas horas e os moradores, que não haviam sido convocados para a reunião, se organizaram e começaram a formar associações rapidamente. Estes cidadãos começam a fazer perguntas: "é razoável enterrar o lixo atômico em nossa cidade?" "Existem outras soluções?" "É prudente confiar nas pesquisas geológicas?” A CEA organiza então dezenas de palestras e distribui centenas de folhetos apresentando o projeto. Os especialistas, pensando que os moradores locais estão sob o domínio de medos infundados, anunciam que realmente não há risco. No máximo, eles admitem, relutantemente, que pode haver um risco muito pequeno, em um futuro muito distante, em um tempo além do que se possa imaginar. De qualquer modo, eles argumentam, não há nenhuma outra solução e é necessário se livrar dos resíduos nucleares de uma vez por todas. Enterrar o lixo atômico é uma necessidade e a solução possível.

Mas, segundo Callon et al. (2011, p. 14), os cidadãos aprenderam a desconfiar de informações fornecidas por agências nucleares, mesmo quando elas parecem estar tecnicamente e moralmente acima de qualquer suspeita. Os cidadãos ainda se lembravam da nuvem de Chernobyl. É por isso que eles preferem recorrer a outras fontes de informação. Uma contraperícia é convidada a dar o seu ponto de vista sobre o projeto. Temas de discussão surgem gradualmente. A ideia de que a armazenagem geológica é a única solução concebível começa a ser qualificada. No calor da polêmica, os moradores percebem que há muitas incertezas e que o soterramento de resíduos radioativos é apenas uma possibilidade e que exigiria longos e complexos estudos científicos. Eles também descobrem que, no passado, outras soluções foram consideradas. Existe a técnica de transmutação, por 
exemplo, a qual, ao garantir a destruição de radionuclídeos com uma vida longa, teria a vantagem de reduzir consideravelmente as incertezas e riscos inerentes à armazenagem geológica.

O conhecimento da existência dessas incertezas científicas e dessas técnicas leva à reformulação dos termos do problema e ao surgimento de novas questões e novos cenários. "E se as gerações futuras encontrarem métodos mais satisfatórios para lidar com estes resíduos?" "Deve-se legar esse lixo à camada geológica e às gerações futuras?" "E se a irreversibilidade do armazenamento for contrária à abordagem satisfatória?" Assim, aquilo que era um fato consumado a solução de cravar fundo na terra os resíduos radioativos - torna-se uma questão em aberto. Os argumentos multiplicam-se e o projeto deixa de ser o quadro tranquilo delineado pelos seus autores. No decorrer da controvérsia, conexões inesperadas são estabelecidas: "e se houver um terremoto, o que pode acontecer com os contêineres?" "E se houver inundações?" "E se algo acontecer com a atmosfera e os humanos precisarem viver no subsolo?" A partir das dúvidas, o que deveria ter sido um projeto técnico simples torna-se uma pluralidade de incertezas e de análise de riscos.

Além disso, novos atores entram em cena e pode-se ver novos e inesperados temas redefinindo as possíveis consequências do projeto. Os moradores assinalam para perigos que os técnicos não poderiam imaginar. Por exemplo, a ameaça que representa a introdução de um centro de armazenamento de resíduos nucleares para a saúde econômica da região. Enquanto os técnicos viam o projeto como fonte de riqueza para a região, os agricultores ponderam sobre a relação que pode ser estabelecida na mente do consumidor entre a qualidade dos produtos agrícolas e a presença de resíduos radioativos. "Você comeria uma batata ou tomaria um vinho produzido sob estas condições?", perguntam os moradores.

Visto por seus autores como uma fonte de desenvolvimento econômico local, o armazenamento de lixo nuclear torna-se uma ameaça potencial para alguns interesses comerciais. Os vereadores, antes aliados do projeto, ansiosos para defenderem os interesses dos seus eleitores, pedem um debate nacional e uma melhor consideração dos aspectos sociais e econômicos do problema.

Ainda, segundo Callon et al. (2011, p. 15), o conflito cresce consideravelmente e se transforma em uma batalha campal. Dos riscos associados com o armazenamento de resíduos radioativos, passa-se a falar agora dos riscos de distúrbios sociais e de revoltas por parte dos que são considerados minorias incontroláveis. Logo, os esquadrões do batalhão de choque são enviados para proteger os técnicos. Ao mesmo tempo, o aumento das manifestações atrai mais e mais pessoas. Os habitantes manifestam a intenção de resistir com violência às decisões do poder central que lhes nega a identidade de seu território.

Para pôr fim ao clima de guerra civil, em 1990, o governo decide voltar atrás e declara uma moratória sobre o projeto que está sendo conduzido pela CEA. Iniciase uma reavaliação do caso e constrói-se um espaço para a consulta a todas as partes interessadas. Pego de surpresa, o governo descobre a existência de instituições que poderiam ser úteis a ele. Busca então a ajuda da Faculdade de Prevenção de Riscos Tecnológicos e do Gabinete Parlamentar para a avaliação das opções científicas e tecnológicas. Finalmente, a lei francesa sobre gestão de resíduos nucleares, a lei de 30 de Dezembro de 1991, surge a partir dessas consultas e discussões. 
Com este exemplo torna-se possível perceber como considerações da dimensão ontológica do conhecimento - que entidades existem no mundo, que relações estas entidades podem manter, como as pessoas reagem a estas entidades e relações, como o mundo pode vir a se comportar no futuro transformam totalmente o caráter de uma questão. Além disso, segundo Callon et al. (2011, p. 16), a lei 30 de Dezembro de 1991 afeta a própria concepção de tomada de decisão política. Não é mais uma questão de decidir, com base em dados científicos indiscutíveis. A lei define um quadro para uma abordagem gradual e que favorece ajustes e correções, isto é, favorece a decisão de não se decidir e, sim, ter tempo para explorar opções possíveis, configurar novos estados possíveis do mundo, antes de se emitir um pronunciamento final. O exemplo tratado acima pode ser esquematizado conforme a figura 1, a qual se apresenta dividida em três regiões distintas.

A região 1 refere-se a uma situação na qual os engenheiros e técnicos respondem a determinado problema com base em seus conhecimentos especializados. A partir da análise dos estados possíveis do mundo - decaimento radioativo, milhões de anos, condições geológicas, isolamento, etc. - e dos riscos envolvidos quando se considera estes estados do mundo, os especialistas configuram um cenário no qual a melhor opção é enterrar o lixo atômico.

Figura 1. Esquema do exemplo matriz de polêmica tecnocientífica
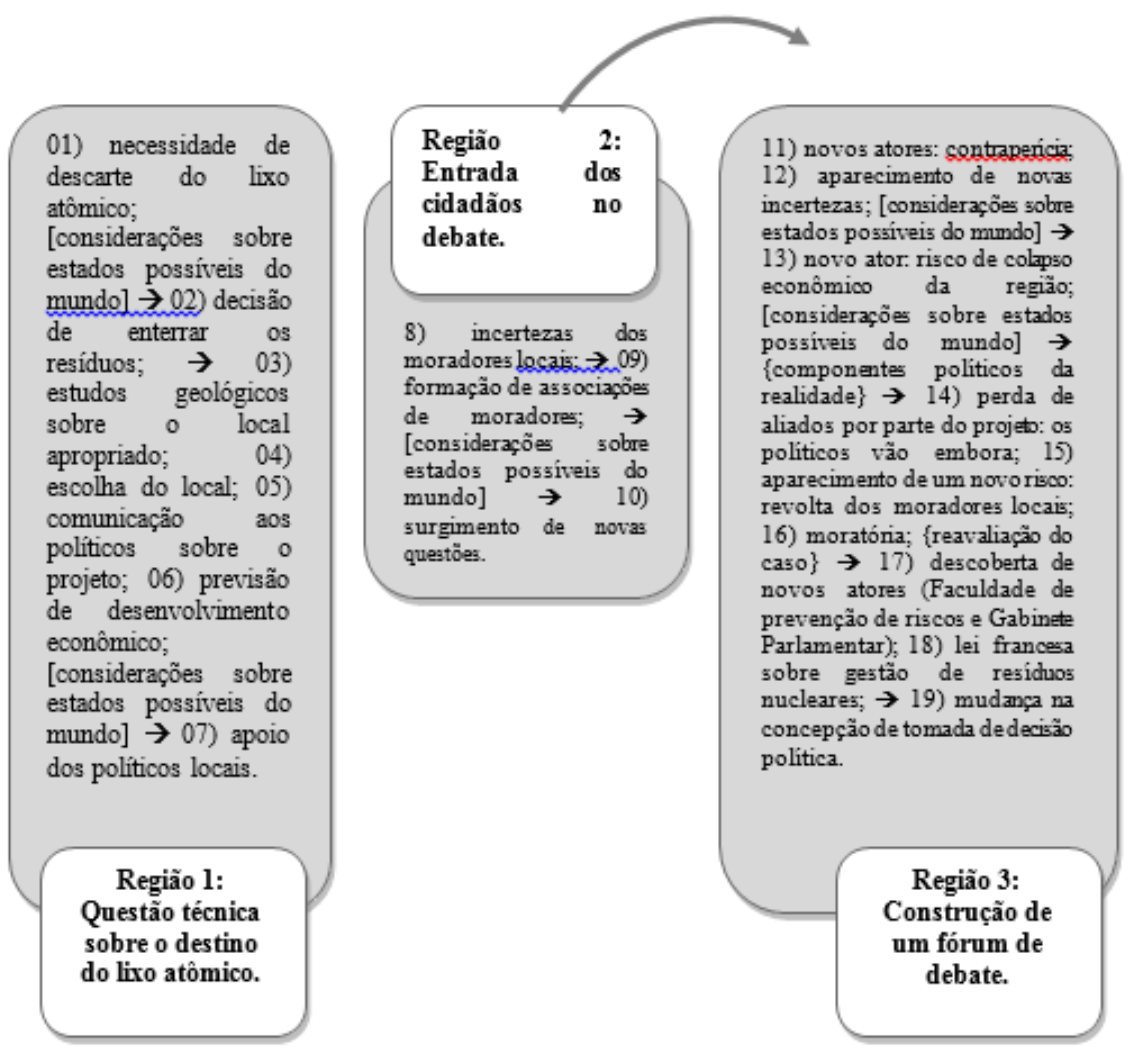

Na região 2, os cidadãos entram em cena. Por não compartilharem com os especialistas dos mesmos elementos na análise dos estados possíveis do mundo, estes sujeitos também não concordam com as mesmas certezas e novas questões 
e possibilidades de riscos são colocados em pauta. Para se ter uma ideia de como especialistas e agricultores estão distantes, basta lembrar um fato: para os especialistas o futuro aparece como inimagináveis milhões de anos à frente; porém, para os agricultores o risco do colapso econômico da região e a possibilidade de falência econômica tornam o futuro algo próximo.

Finalmente, na região 3 tem-se a formação de um fórum de debates e uma tomada de consciência de que uma situação vista como puramente técnica possuía, na verdade, fortes componentes políticos. Segundo Latour (1994, p. 140) um fórum de debateii é um espaço no qual todos têm o mesmo direito de se pronunciar e ser ouvido, tanto aqueles que representam a sociedade, quanto aqueles que representam a natureza. De acordo com este autor, é preciso reconhecer a necessidade urgente de dar espaço e valor às múltiplas vozes que compõem o coletivo social e que engloba as relações entre humanos e nãohumanos. Somente por meio da constituição deste espaço, como apresentado, foi possível que termos como "camada geológica", "radioatividade", "decaimento radioativo", "resíduos nucleares" e "milhões de anos", por exemplo, formassem relações com "economia", "perda de votos", "revolta", "violência", "Gabinete Parlamentar", "batalhão de choque" e outros tantos elementos estranhos a uma questão puramente técnica. Além disso, no exemplo matriz, a resolução do conflito no fórum de debates aparece na forma de uma nova lei sobre a gestão de resíduos nucleares, cuja proposta transforma inclusive a concepção de tomada de decisão política.

Os acontecimentos em cada uma das regiões da figura 1 envolvem sempre a consideração de estados possíveis do mundo. Somente delineando cenários do mundo foi possível propor ações. Em um primeiro momento, os técnicos da CEA, com base em uma lista de entidades do mundo e de suas relações, consideram um estado possível em que soterrar o lixo atômico é a melhor opção. No entanto, esta proposta esbarra em núcleos de incertezas compartilhadas por cidadãos e a contraperícia. Estes, com base em suas próprias listas de entidades subsistentes no mundo e de suas relações, consideram outros estados possíveis e novas realidades aparecem como reguladoras das decisões. Assim, pode-se perceber que a realidade é múltipla e consequência dos métodos pelos quais é abordada.

A noção de realidades múltiplas surge como decorrência das pesquisas desenvolvidas na tradição, que já completa mais de 30 anos, dos chamados estudos de ciência. Tais estudos tornaram amplamente aceito que os processos de produção e distribuição do conhecimento possuem a capacidade gerativa de produzir novas entidades e relações no mundo (RÚBIO e BAERT, 2012, p. 4). Isto significa que os métodos e abordagens ao real possuem efeitos performativos sobre as realidades que se estuda (por exemplo LAW, 2012 e MOL, 2003). Law (2012, p. 156) denomina estas realidades de "realidades colaterais" e as define como realidades criadas ao acaso, sem uma intenção prévia. Mol $(2003$, p. 6) utiliza a expressão "ontologia política" para referir-se à ideia de que a realidade não precede as práticas com as quais um indivíduo interage, antes sendo modelada por essas práticas. A expressão "política ontológica" é explicada pela autora da seguinte forma: 
práticas banais nas quais interagimos com ela, antes sendo modelada por essas práticas. 0 termo política, portanto, permite sublinhar este modo ativo, este processo de modelação, bem como o seu caráter aberto e contestado. (MOL, 2008, p. 2)

Mol (2003) ressalta que, ao longo das últimas décadas, os elementos "estabilidade" e "determinação" foram retirados da composição da realidade. Por meio de um grande trabalho, em boa medida realizado sob a referência da teoria ator-rede (LAW e HASSARD, 1999), estabeleceu-se que a realidade é localizada histórica, cultural e materialmente. Assim, por exemplo, nos estudos de ciência, o laboratório foi redescrito como prática sociomaterial onde a realidade é transformada e onde se concebem novas formas de fazer a realidade. E "se a realidade é feita, se é localizada histórica, cultural e materialmente, também é múltipla" (MOL, 2008, p. 3).

No exemplo matriz apresentado estas realidades colaterais aparecem em diversas ocasiões. Em um primeiro momento, são encontrados os técnicos que haviam representado uma realidade na qual o lixo atômico estaria enterrado de modo seguro dentro de contêineres. Na realidade produzida por seus métodos não havia coisas como terremoto, inundação, desastres atmosféricos, revolta, guarda nacional e falência econômica. Estes novos elementos começam a fazer parte da realidade em um segundo momento, quando novos atores, os moradores locais, entram em cena. Esta nova realidade, manifestada na forma de riscos, incertezas e delineamento de paisagens nas quais haveria, até mesmo, a necessidade dos humanos recorrerem ao abrigo do subsolo, é completamente diferente da primeira criada pelos técnicos.

A realidade dos técnicos envolvia diversos elementos e relações, porém era completamente destituída de elementos axiológicos, tais como identidade dos moradores, revolta, violência e juízos de valor sobre a qualidade dos produtos agrícolas. Estes elementos, portanto, geram uma realidade na qual o comportamento dos atores torna-se componente fundamental.

Figura 2. Inventário de alguns elementos presentes nas três realidades criadas no exemplo matriz

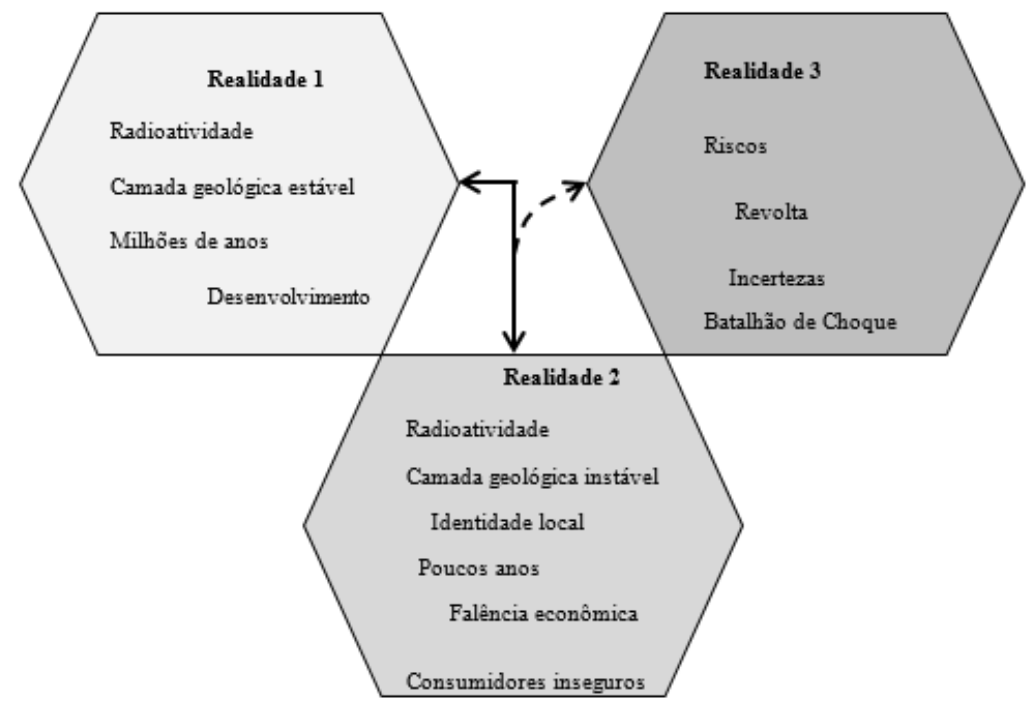


Algo mais notável ainda pode ser dito: o surgimento de um novo artefato funcional na forma de lei sobre gestão de resíduos atômicos. Este novo e inesperado elemento conforma uma realidade na qual se reformula o próprio caráter das decisões políticas. A figura 2 inventaria alguns dos elementos presentes nas realidades dos técnicos (realidade 1), na realidade dos moradores (realidade 2) e uma nova realidade criada pelo embate das duas anteriores (realidade 3 ).

É importante compreender, no entanto, que em uma controvérsia, como a exposta no exemplo matriz, realidades colaterais surgem de diversas formas: novos elementos do mundo natural, novas paisagens do futuro, novos artefatos e novos comportamentos. Portanto, a expressão "realidades colaterais" refere-se de forma ampla a todas estas realidades inesperadas que são geradas em práticasiii.

Neste momento do trabalho as condições são propícias para se fazer uma segunda consideração importante sobre o que está sendo proposto. A primeira foi de ordem ontológica; esta agora é de ordem política. Como pôde-se observar, até determinado momento a questão do descarte do lixo atômico era considerada uma questão técnica. Contudo, essa questão esbarra em núcleos de dúvidas e incertezas ao entrar em contato com novos elementos e relações que configuram novos estados possíveis do mundo e geram, portanto, novas realidades. Estas realidades colaterais, agora com fortes componentes políticos e axiológicos, surgiram somente porque é constituído um fórum de debate, conforme nota-se na região 3 da figura 1 . Portanto, o segundo elemento seria justamente a configuração de espaços que possibilitam o aparecimento das controvérsias, o delineamento de realidades alternativas e a busca de consenso ou adiamento da decisão. Tais espaços serão denominados aqui de espaços de consulta.

Inspirados pelo conceito de fóruns híbridos de Callon et al. (2011, p. 9) e pelos acontecimentos na região 3 da figura 1, espaço de consulta foi definido como uma rede constituída de atores humanos e não-humanos nas quais se confrontam a atividade de pesquisa científica e a gestão política das controvérsias originadas (ou estimuladas) por esta produção (POULIOT, 2008). Os espaços de consulta são pensados como locais de experiências de democracia, no sentido de serem atividades que mobilizam os alunos para a participação e a deliberação democrática sobre questões controversas. Para Callon et al. (2011, pp. 153-189) existiria uma maneira usual, porém desgastada, de gestão política de controvérsias tecnocientíficas chamada de tipo delegativa que impõe uma distribuição assimétrica de papeis relativos à produção de formas legítimas de conhecimento e de autorização concedida aos diversos atores sociais (cientistas, cidadãos, funcionários do governo, políticos e demais grupos da sociedade civil) para expressar seus pontos de vista. Em outras palavras, a gestão de tipo delegativa estabelece uma dicotomia assimétrica entre especialista/leigo e político/cidadão.

Resumidamente, de acordo com o ponto de vista da gestão delegativa, aos cientistas são atribuídas as funções de produção de conhecimento e de informar os leigos; aos políticos cabe a função de representar os interesses dos cidadãos e fornecer orientações para os seus comportamentos. Os cidadãos, por serem concebidos como dotados de um "déficit de informação", devem submeter-se ao "duplo monopólio" da produção de conhecimento legítimo e de representação pública (POULIOT, 2008). Percebe-se que, nesta situação, os cidadãos não têm nenhum papel a desempenhar em relação aos seus próprios interesses (POULIOT, 2008). A figura 4 resume estes papeis. 


\begin{tabular}{|c|c|c|}
\hline \multicolumn{3}{|c|}{ GESTÃO DELEGATIVA } \\
\hline $\begin{array}{c}\text { Cientistas } \\
\text { Produzir conhecimento } \\
\text { * Informar os demais } \\
\text { atores sociais }\end{array}$ & $\begin{array}{c}\text { Políticos } \\
\text { Representar interesses } \\
\text { * Fornecer orientações }\end{array}$ & $\begin{array}{c}\text { Cidadãos } \\
\text { Serem informados }\end{array}$ \\
\hline
\end{tabular}

No entanto, o que o exemplo matriz mostra é outra situação. A entrada em cena dos cidadãos permite o aparecimento de realidades colaterais que ampliaram os termos do debate e, daí, aquilo que era uma solução purgada de toda incerteza e risco se mostra controversa e perigosa. Em oposição a esta gestão de tipo delegativa, Callon et al. (2011, p. 35) propõem uma gestão, em fóruns híbridos, de tipo dialógica. Neste tipo de gestão, considera-se que os cidadãos são capazes de apropriarem-se dos conhecimentos científicos relevantes, relativos aos problemas que estão sendo discutidos, e contribuir para o processo de decisão (POULIOT, 2008). Os dois tipos de gestões podem ser ilustrados conforme a figura 3.

A gestão dialógica concebe as controvérsias como oportunidades que conduzem a uma redistribuição dos papeis relativos à gestão e ao direito de falar, apontando para as vantagens de um modelo democrático participativo. A partir do exemplo matriz, os autores afirmam que os leigos - chamado de "pesquisadores soltos" (researchers in the wildiv) - estão, por conta de seus interesses e experiências únicas, em condições legítimas de contribuir nas discussões e colaborar efetivamente com os cientistas - chamados de "pesquisadores reclusos" (secluded researchers) - na produção do conhecimento válido (CALLON et al, 2011, p. 126). Assim, da perspectiva deste trabalho, à escola cabe a tarefa de contribuir para a formação desses pesquisadores soltos, tal que percebam o potencial de suas contribuições para a gestão dos problemas tecnocientíficos. 
Figura 3. Surgimento de realidades colaterais em função de um espaço de discussão. A solução do problema (ou seu adiamento) é realizada a partir das realidades possíveis. (Ilustração: Gabriela Guerra).

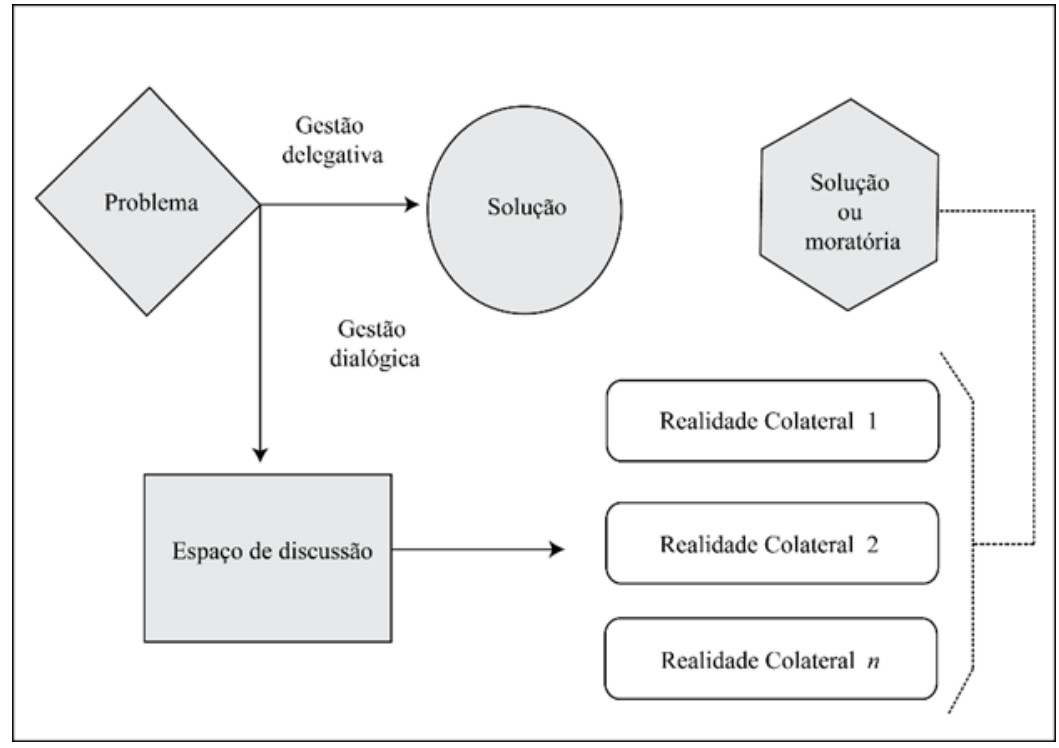

Antes de iniciar a próxima subseção, vale salientar as seguintes consequências do que foi discutido até aqui, por motivos de orientação do leitor sobre aquilo que mais interessa: a) a ciência produz riscos e incertezas; b) a gestão dos riscos e incertezas por parte de especialistas e técnicos é somente uma possibilidade; c) a participação legítima dos cidadãos produz realidades colaterais que ampliam os termos do debate e produz um aprendizado coletivo sobre os estados possíveis do mundo (ou realidades colaterais); d) a participação dos cidadãos deve ser legítima, o que implica um modelo de democracia dialógica ou participativa; e) soluções legítimas devem ser extraídas a partir da deliberação simétrica sobre as realidades colaterais; e, f) a escola torna-se um lugar privilegiado para a construção de conhecimentos, habilidades e valores para a gestão da sociedade.

\subsection{Aprendendo com riscos e incertezas}

Como nota-se, a partir do que já foi explanado, a separação entre ensino de ciências e educação para a cidadania, mencionada na introdução deste artigo, torna-se obsoleta. Desde o momento em que a questão é lidar com as incertezas e riscos disseminados pela produção e circulação do conhecimento científico e tecnológico, coloca-se como papel da escola, em geral, e do ensino de ciência, em particular, contribuir para a formação de cidadãos capazes de colaborar nos espaços de consulta.

A concepção de aprendizagem em ciência considerada aqui se situa, portanto, para além da prática de memorização de fatos e teorias. Corrobora-se, assim, a ideia de que tais conteúdos, indispensáveis no processo de ensino/aprendizagem de ciências, devem servir-se à formação de cidadãos que precisam decidir sobre os rumos da sociedade. Portanto, este trabalho alinha-se à proposta de Hodson (2003), segundo a qual o ensino de ciência deve abarcar quatro níveis de sofisticação, a saber: 
- Nível 1. Aprender Ciência e Tecnologia. Adquirir e desenvolver conhecimento conceitual e teórico sobre Ciência e Tecnologia; tornar-se familiar com o âmbito da tecnologia atual;

- Nível 2. Aprender sobre Ciência e Tecnologia. Desenvolver uma compreensão da natureza e métodos da Ciência e da Tecnologia e tomar consciência das complexas interações entre Ciência, Tecnologia, Sociedade e Ambiente. Tornar-se sensível às consequências pessoais, sociais e éticas de tecnologias particulares;

- Nível 3. Fazer ciência e tecnologia. Engajar na investigação científica e resolução de problemas autênticos. Desenvolver competência no uso de recursos e tarefas tecnológicas; e,

- Nível 4. Engajar na ação sociopolítica. Adquirir capacidade de tomar decisões responsáveis e efetivar ações em relação a tópicos sociais, econômicos, ambientais e éticos.

Embora a atenção aqui seja dirigida principalmente para o nível 4, focando as contribuições que podem ser dadas pelo ensino de ciência para a participação do cidadão no diálogo público sobre os riscos e as incertezas produzidos pela ciência, busca-se construir uma proposta que possa satisfazer também os outros três níveis. Assim, a partir dos níveis propostos por Hodson (2003), o exemplo matriz será analisado a fim de se extrair as consequências para o aprendizado de ciências e para a ação política democrática. Contudo, mais adiante, o estudo demonstrará a possibilidade de mais dois níveis de sofisticação da aprendizagem, para além dos de Hodson.

O texto de Callon et al. (2011), obviamente, não se preocupa com ensino de ciências e, portanto, não fornece elementos suficientes para a descrição de todas as aprendizagens que aconteceram na situação real. Por isso, utilizando um método de experimentos de pensamento (BLOK e JENSEN, 2011, p. 54), esta análise irá extrapolar e imaginar como o exemplo poderia ser utilizado no processo de ensino/aprendizagem em ciências.

Quanto ao nível 1, pode-se perceber que a situação de controvérsia sobre riscos e incertezas tem o potencial de construir um ambiente propício para a aprendizagem de ciência e tecnologia. Para citar alguns, conteúdos da geologia podem estar envolvidos, tais como a formação das camadas geológicas, tipos de rochas e eras geológicas; poderiam ser feitas ligações com paleontologia, a história da vida na Terra e as grandes extinções; a química e a física encontram espaço para introduzir temas como átomos, radioatividade e técnicas de datação; tais conhecimentos podem ser ligados a conteúdos de biologia como genética e biologia molecular; e, as relações entre saúde e ambiente podem ser ricamente exploradas.

Em relação ao nível 2, a situação pode favorecer o aprendizado sobre a natureza da ciência e da tecnologia. Por exemplo, como os conhecimentos científicos são produzidos e legitimados; que garantias são dadas sobre estes conhecimentos; como a tecnologia favorece o desenvolvimento da ciência e viceversa; uma vez que podem ser estabelecidas controvérsias, o que se considera certeza e verdade em ciência, as relações entre hipótese e evidência e a controvérsia epistemológica sobre descoberta ou construção de fatos. É importante notar, no entanto, que tal abordagem deve favorecer a construção de 
uma imagem da atividade científica como uma prática social e inacabada. Melhor do que expor os alunos a uma concepção epistemológica arcaica de conhecimento científico como um repertório factual estático e incontestável é mostrar sua dinâmica e incompletude (ver, por exemplo, JASANOFF, 2012). Se o objetivo é formar cidadãos capazes de atuarem nos diversos fóruns deliberativos da sociedade, uma epistemologia crítica e mais próxima da prática científica deve ser mais desejada do que uma epistemologia que já parta do conhecimento científico como algo pronto, seguro e certo. Caso seja desejado atrair os alunos para as carreiras científicas, nada melhor do que mostrar o quanto a ciência ainda precisa avançar.

Este é um componente importante, pois orienta que se evitem propostas de atividades que colocam os alunos em debates e busca de soluções mas que, ao final, estabelecem um ponto de vista único e correto, que seria o da ciência. Assim, este estudo procurou eleger como referenciais epistemológicos autores dos chamados estudos de ciência, que tratam de temas como modos de produção do conhecimento técnico-científico (GIBBONS et al. 1994), diferentes culturas epistêmicas (KNORR-CETINA, 1981 e 1999), práticas (LATOUR, 2000 e PICKERING, 1995), realidades colaterais (MOL, 2003; CALLON et al., 2011 e LAW, 2012), razão pública (JASANOFF, 2012), e formas de legitimação (DASTON e GALISON, 2007).

A situação analisada também favorece a satisfação das exigências do nível 3 de aprendizagem, uma vez que cria condições para o engajamento em resolução de problemas autênticos. Os problemas autênticos são aqueles considerados complexos, ou seja, em sua estrutura não há o fornecimento de todas as informações necessárias para sua solução. Neste caso, o indivíduo tem de selecionar informações e métodos para obter uma possível resposta (ROTH, 1995). Considera-se que a exploração de um problema autêntico desencadeia uma atitude de investigação e se distancia de estratégias que são empregadas nos tradicionais problemas escolares, estes caracterizados por serem bem definidos e com um resultado ou resposta esperada (LIMA e SILVA, 1997). Além disso, estes problemas podem ser utilizados para a aprendizagem de tecnologias, tais como simulações ou construção de modelos.

Finalmente, quanto ao nível 4, a situação é rica em seu favorecimento. É possível apontar, em primeiro lugar, a aprendizagem sobre participação no coletivo. Como visto, as distinções entre leigo/especialista e ciência/política foram substituídas por cenários que articulam diferentes tipos de considerações. Este deslocamento de um cenário de solução técnica para outro que integra diferentes pontos de vista foi realizado por meio de negociações e compromissos sucessivos entre especialistas e cidadãos (CALLON et al., 2011, p. 32). Portanto, o exemplo sugere que não se trata simplesmente de agregar a visão dos diversos atores, ou avaliar a aquisição de conceitos, fatos e teorias, mas de extrair os resultados de uma aprendizagem coletiva resultante de participação legítima de todos os envolvidos. Assim, o aluno deve perceber-se como agente ativo e capaz de organizar debates e fóruns, propor ações resultantes do embate democrático e como sujeito capaz de influenciar as decisões relativas à gestão da sociedade.

Em segundo lugar, a situação favoreceu a discussão sobre a governança dos resultados da ciência (JASANOFF, 2012). O exemplo matriz mostra que a participação do cidadão é um acréscimo fundamental ao gerenciamento dos conhecimentos normalmente legitimados pelos especialistas. A participação dos cidadãos levou ao questionamento do raciocínio técnico, ofereceu contra- 
argumentos capazes de perturbar a certeza científica e originou novas abordagens ao sistema político e judiciário. Este resultado é importante para orientar a condução desta proposta, pois o que se objetiva é justamente que o aluno perceba que os conteúdos de ciência não são um fim em si mesmos, mas meios de garantir seu direito de conhecer para atuar no mundo e cuidar de si (ver, por exemplo, JASANOFF, 2012, pp. 27-28).

Como anunciado, observa-se que a participação em espaços de consulta sobre riscos e incertezas pode levar a outros dois níveis de sofisticação da aprendizagem, não mencionados por Hodson (2003). O nível 5, diz respeito à capacidade do aluno de integrar conhecimentos, numa perspectiva transdisciplinar. Esta abordagem envolve a colaboração de um conjunto de disciplinas diversas, com seus métodos, técnicas e teorias, centrada na resolução de problemas do mundo real. Portanto, os tópicos de ensino, na configuração que está sendo proposta, devem ser extraídos de problemas reais que permitam explorar uma ontologia da diferença e da multiplicidade, que requer a aceitação de que "um objeto pode pertencer a diferentes níveis da realidade" (THOMPSON-KLEIN, 2004, p. 524), conforme já discutido em relação às realidades colaterais. Pretende-se, portanto, que um dos resultados finais de um processo de ensino na perspectiva desse trabalho seja a formação de um conhecimento híbrido que, por sua vez, seja maior do que soma das partes (LEAVY 2011, p. 31).

Em relação ao outro nível de aprendizagem a ser sugerido, o nível 6, vale salientar que talvez seja o mais abstrato e o que requer maior criatividade, porém é aquele com maior poder de transformação da realidade. Trata-se da configuração de estados futuros do mundo. Este nível permeia os campos da utopiav e da futurologia, dimensões esquecidas nos processos educacionais contemporâneos (HICKS, 2002). No exemplo matriz, incertezas surgiram, cálculos de riscos foram realizados e decisões foram tomadas graças à construção de cenários futuros que emergiram e conformaram o curso das decisões - como, por exemplo, situações que obrigariam os humanos a fazerem uso de moradias no subsolo.

Esta situação, a elaboração de estados futuros do mundo, não é algo distante da vida cotidiana. Uma série de decisões que precisam ser tomadas e tarefas que precisam ser executadas rotineiramente são realizadas justamente para se atingir ou evitar determinados estados futuros do mundo. Assim, por exemplo, um aluno que constrói um cenário futuro no qual ele cursa uma boa universidade sabe que deverá construir condições para que este estado de mundo seja concretizado. Em outras palavras, "imagens do futuro estão entre as causas do comportamento presente" (BELL, 2002, p. XII).

Para entrar na dimensão utópica do pensamento, o aluno deve mobilizar fortemente suas capacidades de abstração e criatividade, pois é a partir da avaliação dos estados do mundo e por meio de ideias reguladoras gerais - tais como "que entidades subsistem no mundo", "como o mundo se comporta", "como as pessoas se comportam", "o que leva as pessoas a mudarem seus comportamentos" etc. - que poderá mover-se para estados futuros possíveis do mundo, delinear cenários desejáveis, projetar as ações cabíveis, clarificar os seus valores, pensar sobre mudança e sobre a temporalidade e adquirir uma visão processual da realidade. 
Este nível de aprendizagem é de fundamental importância para a ação política, uma vez que aquilo que as pessoas decidem fazer depende não somente de suas crenças sobre o que é possível e provável sob certas condições, mas inclusive depende de suas habilidades para julgar aquilo que é desejável (HICKS, 2002, p. XII). Neste caso, então, uma preocupação desta proposta é que este nível de aprendizagem seja satisfeito. Para tanto, pode-se pensar como estratégia a busca de resposta à questão "em que mundo deseja-se viver?" Esta mediação reforça o anacronismo da separação entre aprendizagem de conteúdos científicos e educação para a cidadania, pois congrega elementos do conhecimento científico, da política e da ordem dos valores éticos.

\section{CONFIGURANDO O ENSINO DE CIÊNCIAS PARA A AÇÃO DEMOCRÁTICA: UMA PROPOSTA METODOLÓGICA.}

Como se conclui, a gestão de riscos e incertezas tecnocientíficos cria situações oportunas para a aprendizagem coletiva sobre conteúdos de ciência, participação política e planejamento de estados futuros do mundo. A partir destas constatações propõe-se uma metodologia de inserção destas discussões na escola, por meio de uma correlação entre os aspectos destacados no esquema do exemplo matriz (figura 1) e os seis níveis de sofisticação que o ensino de ciências deve contemplar, como discutido na seção anterior. Isso significa que se tem o intuito de fornecer um suporte, uma orientação metodológica para futuras elaborações de estratégias de ensino que venham promover uma formação dos estudantes para a ação democrática e para a cidadania. A figura 5 sistematiza as etapas e características dessa proposta.

Figura 4. Configuração metodológica para o ensino de ciências e ação política democrática. (Ilustração: Gabriela Guerra).

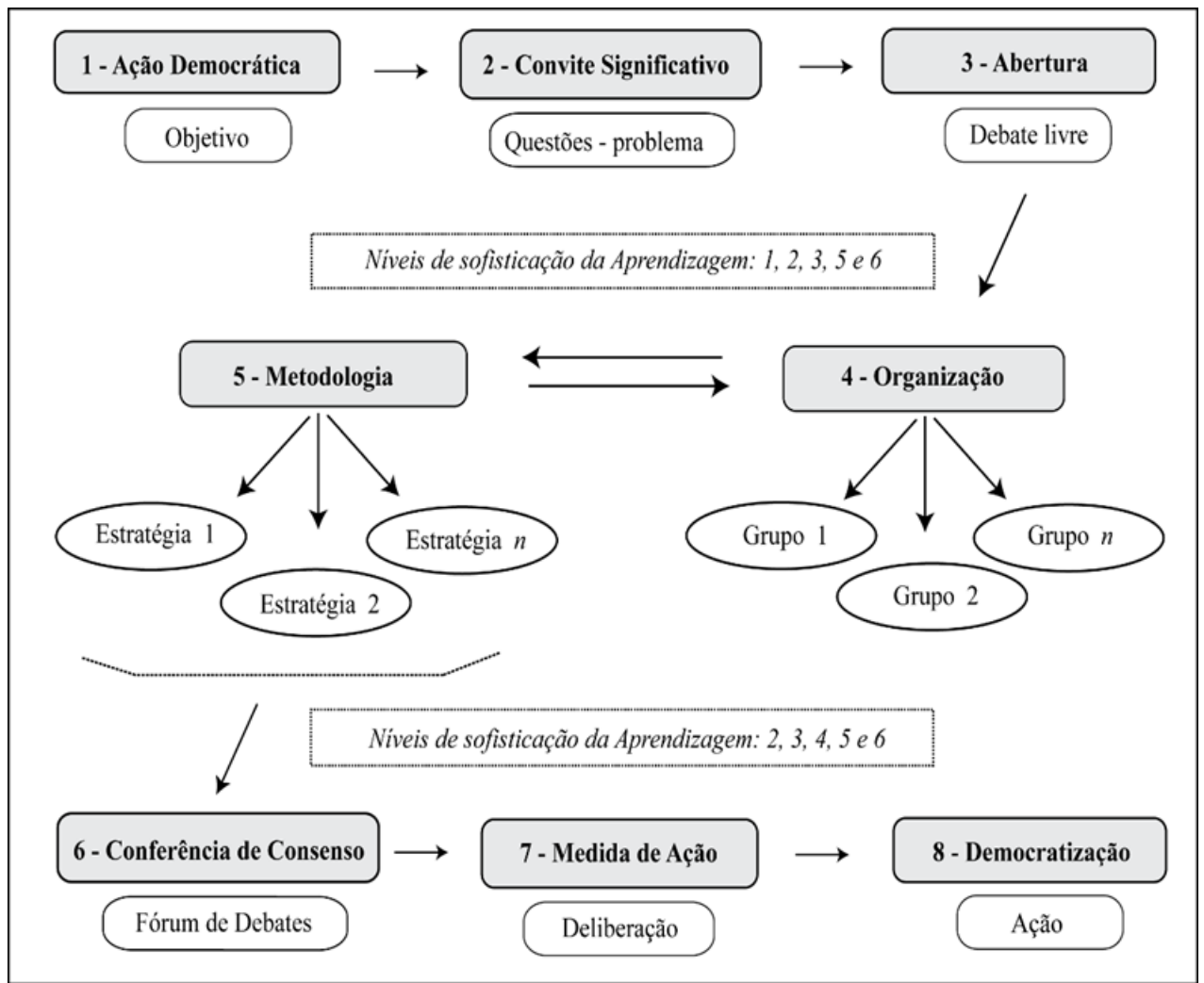

R. bras. Ens. Ci. Tecnol., Ponta Grossa, v. 9, n. 1, p. 380-406, jan./abr. 2016. 
Obviamente, o planejamento de uma estratégia de ensino deve iniciar-se pela delimitação de seus objetivos. Entretanto, raramente é dada a oportunidade aos alunos de participarem dessa etapa ou mesmo de tomarem conhecimento explicitamente dos objetivos traçados pelo professor. Sendo assim, esta configuração inicia-se com uma etapa que será chamada de ação democrática. A coincidência é intencional. Uma vez que a intenção é motivar práticas que orientem os estudantes a tomarem uma postura crítica e política frente a questões tecnocientíficas, deve-se também começar a promover um ensino mais democrático, por exemplo, compartilhando e discutindo com os alunos sobre as metas de uma estratégia de ensino. Nessa perspectiva, a primeira etapa do diagrama pressupõe uma explicitação por parte do professor dos objetivos da atividade, discussões e negociações coletivas sobre estes, caso necessário, até que se chegue a uma delimitação consensual. É fundamental para se manter uma coerência interna no processo que esse caráter democrático perpasse todas as etapas.

Uma vez que todos os envolvidos estejam devidamente cientes e acordados em desenvolver uma atividade cujo objetivo geral será deliberar sobre problemas cotidianos envolvendo a tecnociência, passa-se para a segunda etapa que se refere à escolha de uma questão tecnocientífica significativa, no sentido de que é um problema autêntico que envolve riscos ou incertezas em relação às suas consequências para sociedade. Esta etapa será chamada de convite significativo. Tal convite pode ser realizado pelo professor ou pelos alunos, o mais importante é que todos os convidados estejam igualmente envolvidos e percebam o tema como carregado de riscos e incertezas decorrentes do conhecimento tecnocientífico.

Em seguida, tendo em mente que uma primeira preocupação concerne às questões de exploração de mundos possíveis e de organização de atividades de investigação, com vista à produção de conhecimentos em uma composição coletiva de alunos, estabelece-se que o número e a diversidade de opiniões que são mobilizadas fornecem um critério para estruturar o espaço de debates. Apropriando-se de um termo de Callon et al. (2011, p. 159) denomina-se esta etapa de abertura: os alunos devem ser convidados a expressar as suas opiniões, trocar os seus pontos de vista e negociar em um debate livre. Quanto maior a diversidade de opiniões, mais significativo será o debate. Neste momento, uma mediação do professor é importante para garantir bons resultados da discussão, em termos de sua seriedade. O professor deve estar preparado para intervir e negociar sem muitos pré-conceitos, pois aquilo que parece uma insensatez à primeira vista pode, na verdade, fazer parte de uma realidade colateral bastante fecunda.

Chega-se então o momento de constituir os grupos de trabalho. Estes grupos devem ser estruturados conforme as identidades dos alunos em relação às suas opiniões. Etapa que é chamada de organização. Aqui é importante que os alunos tenham autonomia para identificar estas identidades e formarem os grupos. A permanência em um grupo, no entanto, não deve ser tomada como algo garantido. Ao longo do trabalho, os componentes do grupo devem avaliar a coerências das opiniões e a seriedade em relação ao trabalho. Não se trata de um processo de exclusão, mas de uma decisão política que visa manter a seriedade do trabalho e a coerência dos participantes em relação às posições defendidas. Além disto, devese ter em mente que a composição de um grupo pode mudar em função da etapa seguinte, quando os alunos terão oportunidade de aprofundar a investigação. Alguém que saia de um grupo pode se alinhar a outro ou, por meio de negociações, 
formar um novo grupo. O professor pode monitorar essa etapa questionando os alunos em relação às suas justificativas para a formação do grupo, convergências de ideias e as convicções defendidas.

Uma intervenção intencional deve ser planejada pelo professor no sentido de explorar o potencial dessa etapa quanto aos seguintes níveis de sofisticação da aprendizagem: (i) aprender sobre e fazer C e T - na medida em que os alunos tomam consciência das complexas interações entre Ciência, Tecnologia, Sociedade e Ambiente ao mesmo tempo em que se engajam na investigação científica e resolução de problemas autênticos; (ii) integrar conhecimentos e configurar estados futuros do mundo - na medida em que as ponderações e previsões feitas pelos estudantes não se restringirão a disciplinas isoladas uma vez que isso seria incoerente à concepção do mundo real.

O quinto momento é quando os grupos estabelecem as estratégias investigativas para sustentar suas opiniões. Etapa esta denominada metodológica. As investigações podem envolver diversas estratégias, entre as quais: consulta a especialistas, estudos teóricos, simulações, construção de modelos e consulta à população. Os alunos devem ser encorajados a buscarem informações com os professores das ciências humanas. As diversas áreas do conhecimento têm muito a acrescentar na compreensão, por parte dos alunos, sobre a diversidade de métodos investigativos, o que é fundamental para uma visão transdisciplinar de produção do conhecimento (DOMINGUES, 2003).

Com relação ao papel do professor, levando em conta que a maior parte dessa etapa deve ser cumprida pelos alunos com ações extraclasses, é fundamental que o docente elabore estratégias para monitorar as atividades realizadas pelos alunos, tanto para qualificá-las quanto para auxiliar os estudantes a desenvolverem as competências procedimentais necessárias. Quanto aos níveis de sofisticação da aprendizagem, essa etapa, bem como a relação dinâmica que ela estabelece com a etapa anterior (ao permitir a reorganização dos grupos, novas alianças etc.), não só potencializa os aspectos pontuados para a quarta etapa, como inclui aprender $\mathrm{C}$ e $\mathrm{T}$ - na medida em que exige do aluno adquirir e desenvolver conhecimento conceitual e teórico sobre Ciência e Tecnologia para elaborar e defender suas teses.

Uma vez que os grupos tenham elaborado suas investigações e fundamentado seus conhecimentos, é chegado o sexto momento, quando se constitui um fórum de debates. Este é o momento de uma gestão dialógica, no qual os grupos terão a oportunidade de apresentar os resultados de suas investigações e de propor soluções para o problema em pauta. A esta etapa, novamente por apropriação de uma expressão de Callon et al. (2011, p.2), dá-se o nome de conferência de consenso. Tal etapa é definida pela resposta à questão "em que mundo deseja-se viver?" e a mediação do professor deve favorecer uma qualidade satisfatória da solução encontrada em função da resposta à questão. Deve-se, ainda, considerar a possibilidade de moratória, uma vez que os alunos podem decidir, à luz de evidências teóricas e empíricas, que ainda não há conhecimentos suficientes disponíveis para se tomar uma decisão.

Nesta etapa o professor deve buscar garantir o engajamento de todos os alunos, um debate dialógico e simétrico e o máximo grau de realidade (isto é, às discussões e às deliberações. Além disso, entende-se ser relevante que o 
professor promova uma auto-reflexão sobre o processo vivenciado para favorecer que o aluno sofistique sua aprendizagem a ponto de (i) reconhecer a existência de controvérsias no contexto da $\mathrm{C}$ e $\mathrm{T}$, avaliar criticamente os diferentes pontos de vista, bem como entender das estratégias e recursos mobilizados nos espaços de debates - aprender sobre e a fazer C e T; (ii) perceber sua atuação como a de um cidadão engajado politicamente, provido de conhecimentos diversos e relevantes e portanto, capaz de tomar suas próprias decisões após: analisar criticamente o problema; construir e defender suas próprias teses (estados futuros do mundo); ouvir e ponderar as teses dos outros (novos estados futuros do mundo) - engajar na ação sociopolítica, integrar conhecimentos e configurar estados futuros do mundo.

O sétimo momento envolve uma alta participação do professor. Propõe-se que esta etapa seja chamada medida de ação. Ainda que o professor deva favorecer a autonomia dos estudantes, nesta etapa é importante que ele direcione o processo visando relacionar os riscos e incertezas produzidos e disseminados pelo conhecimento tecnocientífico, as realidades que foram criadas e as soluções que foram dadas pelos alunos em função destas realidades. Neste momento, planeja-se a etapa final.

A oitava e última etapa, a qual se denomina democratização, é aquela em que os alunos produzem coletivamente, se houver consenso na sala, ou em grupos, que tenham opiniões semelhantes, um artefato. Este pode ser um artigo, uma sugestão de lei, uma carta, um blog, uma homepage, um congresso, uma visita programada à Câmara de Vereadores ou à Assembleia, um jornal mural, uma manifestação pública na escola ou espaços e organizações no bairro - enfim, as possibilidades são muitas. O que importa nesta etapa é que os alunos percebam o valor dos conhecimentos adquiridos, o que ainda precisa ser conhecido e a necessidade de engajamento político dos cidadãos. A intervenção do professor nesta etapa deve-se focar na qualidade do(s) artefato(s) produzido(s) e, posteriormente, em uma depuração de todo o processo. Essas duas últimas etapas têm um caráter conclusivo e por isso, sendo bem executadas, potencializam os aspectos de sofisticação da aprendizagem enfatizados na etapa 6 .

Com essa configuração metodológica de ensino de ciências acredita-se favorecer uma autêntica educação voltada para a cidadania, bem como contemplar potencialmente os seis níveis de sofisticação da aprendizagem.

\section{CONSIDERAÇÕES FINAIS}

Ao ser delineada uma proposta para o tratamento do conhecimento científico e a ação política, várias reflexões e questões surgiram e serão compartilhadas a seguir.

Pode-se pensar, inicialmente, na necessidade de aprimoramento de recursos para comparar e avaliar as decisões tomadas pelos grupos de trabalho. Como se trata de, ao final dos trabalhos dos alunos, propor soluções ou decidir adiar uma solução, é preciso estar mais claro sobre que bases as decisões foram tomadas. Por isto, esta proposta precisa ser posta em prática e buscar contribuições das teorias de análise de risco e de tomada de decisão. Além disto, é necessário poder avaliar até que ponto as soluções encontradas foram conseguidas graças a um alto grau 
de dialogicidade, bem como, apresentar contribuições que possam introduzir formas de avaliar este componente da proposta.

Outras questões importantes que se colocam são relativas à formação de professores. Há que se pensar que só se ensina aquilo que se sabe. Deste modo, para preparar o aluno para a vida democrática, o professor também deve estar preparado. Assim, pode-se perguntar: isso tem acontecido nos cursos de licenciatura? Que visão os professores têm sobre o ensino de ciências e a ação política? Como os professores pensam suas identidades e seus papeis na construção de uma sociedade mais democrática? Que recursos teóricos ou estratégias de formação são necessários para que os professores engajem-se em atividades que questionam o poder das disciplinas que eles ministram? Questões similares podem ser postas para o relacionamento do professor com outras disciplinas. Nessa direção, a proposta favorece a ruptura de fronteiras entre disciplinas e mostra como um objeto ou conceito pode pertencer a diferentes campos do conhecimento. No entanto, os professores são formados para este diálogo disciplinar? Como se configuram seus currículos? Que aberturas para o diálogo disciplinar encontram em sua formação? O que é preciso fazer para que esta formação interdisciplinar aconteça?

Este estudo ressalta que uma guinada na filosofia educacional e uma proposta efetiva de prática desta filosofia colocam importantes questões para a formação de professores de ciências. Embora a preocupação inicial seja com o ensino de ciências e cidadania, o artigo sugere questões que ultrapassam este âmbito e dizem respeito à configuração da própria escola. Aprender a vida democrática não é uma questão de adestramento, mas de vivência e exercício. Assim, como estabelecer tempos e espaços para o exercício da democracia na escola? Como romper as rígidas barreiras entre as disciplinas e possibilitar que diferentes visões tenham igual direito à voz? Que condições são necessárias para que a escola abrigue a maior diversidade de sujeitos e opiniões possíveis? Como fazer a dialogicidade estender-se para as relações da escola com as famílias e com o bairro? Assim, o que foi colocado aqui é um passo inicial no caminho de uma reflexão e constituição de uma linha de pesquisa que procura entender as consequências para a educação de se querer viver em uma sociedade mais justa, igualitária e democrática. Neste sentido, o artigo é, ele próprio, a busca de um estado futuro do mundo e, neste sentido, utópico. 


\title{
A setting for science teaching committed to democratic political action: Methodological proposed
}

\begin{abstract}
The article is a programmatic text that aligns the learning of scientific knowledge with the democratic political action. Initially, it presents a tendency in the philosophy of education that is concerned with the learning content and the social and political life of the student. At the same time, it tries to show that, regarding the management of scientific knowledge, the effectuation of this proposal is an urgent need, since science produces and circulates knowledge that has profound impacts on society. Finally, it outlines a methodological proposal for the treatment of the scientific knowledge and the political action. Questions about the improvement of this proposal and teacher training are placed in the final considerations.
\end{abstract}

KEYWORDS: Political action. Science education. Collateral realities. Transdisciplinarity. Consultation spaces. 


\section{AGRADECIMENTOS}

Os autores são gratos ao CNPq e à FAPEMIG pelo apoio financeiro. O primeiro autor é grato ao CNPq pela bolsa de produtividade em pesquisa.

\section{NOTAS}

1 No artigo, como será visto mais adiante, será feito uso do conceito de democracia dialógica, por coerência com CALLON et al. (2011), um dos referencias utilizados para a construção da proposta apresentada. De qualquer modo, vale aqui definir que, fundamentalmente, trata-se de um modelo que legitima a participação pública dos cidadãos nos problemas legislativos. Para isto, a democracia deliberativa evoca os ideais da legislação racional, política participativa e autogovernança cívica (BOHMAN e REHG , 1997).

2 Latour (1994, p. 140) chama de parlamento das coisas.

3 Poderia ainda, por exemplo, ser feita referência a situações em que elementos de ordem estética seriam considerados. Neste caso, tem-se o surgimento de realidades que envolveriam aspectos do mundo com a capacidade de solicitar nossa atenção sensível. Estas realidades são constantemente criadas: o surgimento de espaços sonoros, novas paisagens, formas arquitetônicas, entre outras. Por exemplo, a decisão de preenchimento de uma paisagem com concreto ou com um jardim produz realidades estéticas completamente diferentes. Obviamente, o ensino de ciências poderia facilmente estar envolvido nestas questões. No entanto, considerar este componente no presente artigo fugiria aos objetivos propostos. Fica anotado, no entanto, que este componente precisa ser desenvolvido em artigo posterior.

4 Encontrar uma tradução que capte o significado desta expressão em português é muito difícil. Poderia significar pesquisadores no campo ou pesquisadores em contexto. No entanto, como no texto ela é contraposta a secluded researchers, que se refere aos pesquisadores confinados ao laboratório, preferimos traduzir por pesquisadores soltos.

5 O termo "utopia" muitas vezes é utilizado pejorativamente como quimera, delírio e insensatez. No entanto, seguindo Domigues (2003), ele será tomado positivamente, no sentido de "não-lugar, daquilo que ainda não foi realizado, mas que é uma busca". A utopia é entendida como um modelo que permite uma crítica da organização social vigente, que "faz a humanidade se inquietar, não se conformar com padrões estabelecidos" (DOMINGUES, 2003).

\section{REFERÊNCIAS}

APEDOE, X. S. Engaging Students in Inquiry: Tales From an Undergraduate Geology Laboratory-Based Course. Science Education, v. 92, n., p. 631-663, 2008.

BECK, U. Risk society. Los Angeles: SAGE, 1986. 
BELL, W. Foreword: preparing for the future. In: HICKS, D. W. Lessons for the future. The missing dimension in education, pp. XI-XVI Victoria: Trafford, 2002.

BLOK, A. e JENSEN, T. E. Bruno Latour. Hybrid thoughts in a hybrid world. London: Routledge, 2011.

BOHMAN, J. e REHG, W. Introduction. In: BOHMAN, J. e REHG, W. Deliberative Democracy. Massachusetts: MIT Press, 1997.

CALLON, M.; LASCOUMES, P. e BARTHE, Y. Acting in an uncertain world. Cambridge: MIT Press, 2011.

COLUCCI-GRAY, L.; PERAZZONE, A. e DODMAN, M. Science education for sustainability, epistemological reflections and educational practices: from natural sciences to trans-disciplinarity. Cultural Studies of Science Education, v.8, n.2, p. 127-183, 2012.

DASTON, L. e GALISON, P. Objectivity. New York: Zone Books, 2007.

DOMINGUES, I. Humanidade inquieta. Diversa, 2. Disponível em https://www.ufmg.br/diversa/2/entrevista.htm, 2003. Acesso: 07/05/2015.

FENSHAM, P. Changing the drivers for science education. Canadian Journal of Science, Mathematics and Technology Education, v.2, n., p. 9-24, 2002.

GIBBONS, M.; CAMILE, L.; SCHWARTZMAN, S.; NOWOTNY, H.; TROW, M. and SCOTT, P. The new production of knowledge: The dynamics of science and research in contemporary societies. London: Sage, 2004.

HICKS, D. W. Lessons for the future. The missing dimension in education. Victoria: Trafford, 2002.

HODSON, D. Time for action: science education for an alternative future. International Journal of Science Education, v.25, n.6, p. 645-670, 2003.

JASANOFF, S. Politics of public reason. In: RUBIO, F. D. and BAERT, P. The politics of knowledge, pp. 1-32. London: Routledge, 2012.

KANESHIRO, K. Y.; CHINN, P.; DUIN, K. N.; HOOD, A. P.; MALY, K. e WILCOX, B. A. 
KNORR-CETINA K. The manufacture of knowledge. An essay on the constructivist and contextual nature of science. England: Pergamon Press, 1981.

KNORR-CETINA, K. Epistemic cultures. Cambridge: Havard University Press, 1999.

KOLSTO S. D. Scientific literacy for citizenship: tools for dealing with the science dimension of controversial socio-scientific issues. Science Education, 85(3): 291310, 2001

KOLSTO S. D. Science education for democratic citizenship through the use of the history of science. Science \& Education, v.17, n. 8-9,p.977-997, 2008.

LATOUR, B. Jamais formos modernos. Rio de Janeiro: Editora 34, 1994.

LATOUR, B. Ciência em ação. Como seguir cientistas e engenheiros sociedade afora. São Paulo: Editora da UNESP, 2000.

LAW, J. Collateral realities. In: RUBIO, F. D. and BAERT, P. The politics of knowledge, pp. 156-178. London: Routledge, 2012.

LAW, J. e HASSARD, J. (Orgs.). Actor Network Theory and After. Oxford: Blackwell, 1999.

LEAVY, P. Essentials of transdisciplinary research. Walnut Creek, CA: Left Coast Press, 2011.

LENTZOS, F. e SILVER, P. Synthesis of viral genomes. In: TUCKER, J. B. Innovation, dual use, and security, p. 133-146. Cambridge: MIT Press, 2012.

LIMA, M. E. C., SILVA, N.S. Estudando os plásticos: tratamento de problemas autênticos no ensino de química. Química nova na escola, n.5: 06-10, 1997.

MARTINI, B. e RIBEIRO, C. G. Antropoceno. A época da humanidade? Ciência Hoje, v.48, n.283, p. 38-43, 2011.

MOL, A. The Body Multiple: Ontology in Medical Practice. Durham: Duke University Press, 2003. 
POULIOT, C. Students' inventory of social actors concerned by the controversy surrounding cellular telephones: a case study. Science Education v. 92, n.3, p. 543 $-559,2008$.

REICH, W. Deliberative democracy in the classroom: a sociological view. Educational Theory, v.57, n.2, p. 187-197, 2007.

ROBERTSON, E. Teacher education in a democratic society, In: COCHRAN-SMITH, M., FEIMAN-NEMSER, S., McINTYRE, D. J. and DEMERS, K. E. Handbook of research on teacher education. p. 27-44. New York: Routledge, 2008.

ROTH, W-M. Authentic School Science: Knowing and Learning in open-inquiry science laboratories. Dordrecht: Kluwer Academic Publishers, 1995.

ROTH, W.-M. and DÉSAUTELS, J. (Eds.). Science education as/for sociopolitical action. New York: Peter Lang, 2002.

RUBIO, F. D. and BAERT, P. Politics of Knowledge. An introduction. In: RUBIO, F. D. and BAERT, P. The politics of knowledge. p. 1-10. London: Routledge, 2012.

THOMPSON-KLEIN, M. Prospects for transdisciplinarity. Futures, v.36, n.4, p. 515526, 2004.

VAN BREDA, J. Towards a transdisciplinaty hermeneutics. The global spiral ejournal, 8 (3), Online: http://www.learndev.org/dl/BtSM2007/JohnVanBreda.pdf. 2007. Acesso em 07/05/2015.

WAGHID Y. Action as an educational virtue: toward a different understanding of democratic citizenship education. Educational Theory v.55, n.3, p. 323-243, 2005. 
Recebido: 07 mai. 2015

Aprovado: 19 abri. 2016.

DOI: $10.3895 /$ rbect.v9n1.2935

\section{Como citar:}

COUTINHO, F. A.; FIGUEIREDO, K. L.; SILVA, F. A. R. Proposta de uma configuração para o ensino de Ciências comprometido com a ação política democrática. Revista Brasileira de Ensino de Ciência e Tecnologia, v. 9, n. 1, p. 380-406, jan./abr. 2016. Disponível em:

<https://periodicos.utfpr.edu.br/rbect/article/view/2935>. Acesso em: XXX.

\section{Correspondência:}

Francisco Ângelo Coutinho

Av. Antônio Carlos, 6627, Pampulha, Belo Horizonte, MG, CEP 31270-901

Kristianne Lina Figueiredo

Campus Florestal, Rodovia LMG 818, km 06, Florestal/ MG, CEP: 35.690-000.

Fábio Augusto Rodrigues e Silva

Campus Universitário Morro do Cruzeiro, CEP 35400-000, Ouro Preto, MG, Brasil.

Direito autoral: Este artigo está licenciado sob os termos da Licença Creative Commons-Atribuição 4.0 Internacional.

\section{(c) (1)}

